\title{
Opportunities - New Business Models, Pricing, and Use Cases
}

\author{
Peter McCarthy-Ward ${ }^{1}$, Andy Valdar ${ }^{2}$, Stuart Newstead $^{3}$, and Stuart Revell ${ }^{4}$ \\ ${ }^{1}$ Freelance Lecturer \& Consultant, British Telecom retired \\ ${ }^{2}$ University College London \\ ${ }^{3}$ Ellare \\ ${ }^{4}$ RTA Communicating Systems Ltd
}

https://doi.org/10.26636/jtit.2021.152221

\begin{abstract}
This paper addresses how network operators may gain a reasonable return on their investment into $5 \mathrm{G}$ infrastructure. It first considers the $5 \mathrm{G}$ mobile network costs structure then applies this to three typical use cases.
\end{abstract}

Keywords-5G services, business challenges, infrastructure.

\section{Introduction}

The drive to build and operate $5 \mathrm{G}$ networks continues to be a priority for policymakers across the world. The pressure on mobile network companies to transition rapidly to $5 \mathrm{G}$ platforms and services is immense. Less attention has been given to how those investing in $5 \mathrm{G}$ infrastructure will make a reasonable return on their investment. This paper considers some of the opportunities available to $5 \mathrm{G}$ investors and some of the constraints and limitations on how those opportunities may be exploited. We begin with an examination of pricing in relation to network services, then turn to the cost structure of 5G networks, and finally look at how 5G's new network features can support new revenue growth.

\section{Pricing}

The costs of producing a product are recovered through pricing. The microeconomic theory of pricing is charmingly straightforward. It states that the price for a good will settle at the point where supply matches demand. That point of equilibrium is reached when the price a customer is willing to pay matches the marginal cost incurred in producing the good. If the price is higher demand will drop. If the price is lower there is no incentive to supply. Marginal cost is the cost added by producing an additional unit of supply.

For the theory to hold, certain simplifying assumptions have to be made - such as effective competition, buyer rationality, perceived value, portfolio independence and cost recov- ery timescales. This said, Fig. 1 provides a good summary of the fundamentals, showing that supply equals demand at the intersection of P1 and V1, when the price (and marginal cost) will be P1.

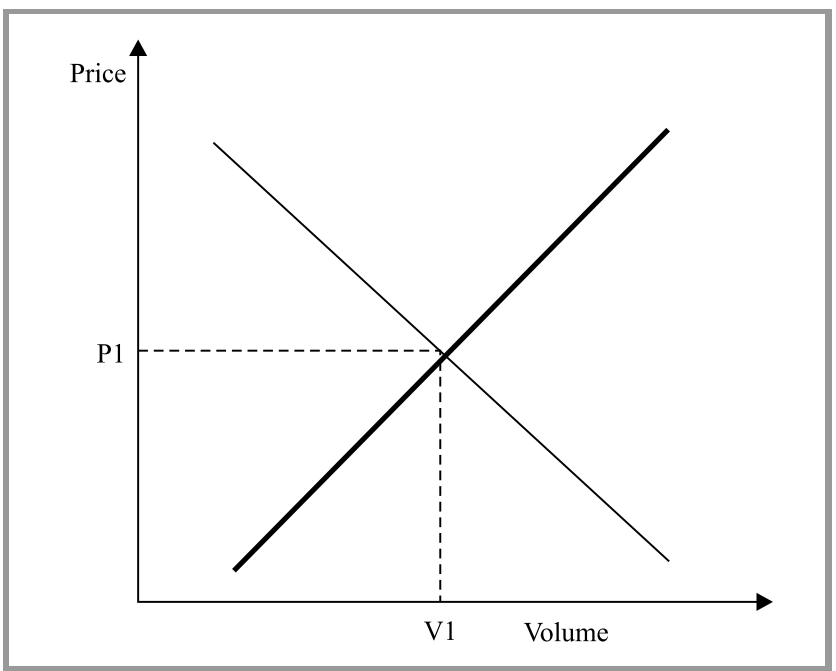

Fig. 1. Price-volume relationship.

The simplifying assumptions of microeconomic theory become particularly relevant when considering network pricing. Communication networks have very high fixed costs and very low variable costs. Network marginal costs rise as a stepped function. The cost of an incremental megabyte of traffic is close to zero, until network capacity is exhausted. The next megabyte requires network expansion and has a huge marginal cost. It is for this reason that regulators often look at long run incremental costs (the cost of providing the whole product or service) rather than marginal costs (the cost of providing a unit of that product or service) when considering regulated prices and interconnection. A network can supply a portfolio of services, and network operators have options over how to recover fixed costs across that portfolio. 
Network operators also have the choice (or a regulatory obligation) to offer wholesale as well as retail services. Here the consideration is the balance to be struck between the potential for better loading of network capacity, and the risk to retail volumes and prices of supporting a competing mobile virtual network operator (MVNO).

High capacity digital networks have led to new forms of competition. What were traditional network services such as text messaging and voice traffic are now supplied by over-the-top providers (OTTPs). New on-line services such as video content, broadcast and catch-up TV and so on, once seen as the future for operators, are increasingly dominated by more fleet-footed OTTPs. Here the risk to operators is not simply the foregone added value opportunity, but also the price volume P1-V1 possibility of network services becoming bundled with OTT packages with the choice of operator moving from the consumer to the OTTP.

These complications and refinements above and beyond basic microeconomic theory make network service pricing particularly challenging. We next consider how 5G cost structures differ from those of current networks, and how its features change the service and portfolio options available to network operators.

\section{3. $5 \mathrm{G}$ Costs}

$5 \mathrm{G}$ specifications relating to the air interface were agreed in 2017 and for the 5G architecture in 2018. Later work is addressing the specification of the $5 \mathrm{G}$ next generation core (NGC). Initial deployments of $5 \mathrm{G}$ networks thus precede the availability of NGC equipment and will rely on the cores of existing $4 \mathrm{G}$ networks. While eventually, the $5 \mathrm{G}$ network will become stand-alone and capable of providing an omnipotent facility covering fixed and mobile communications, there will be a period of parallel running of $4 \mathrm{G}$ and $5 \mathrm{G}$.
$5 \mathrm{G}$ 's use of higher frequency bands $(3.4,3.8$, and 24.25 to $27.5 \mathrm{GHz}$ ) gives greater user bandwidth, but at the expense of reduced cell sizes. However, new spectrally-efficient forms of multiplexing the data onto the radio carriers together with the use highly directional multiple input multiple output (MIMO) antenna technology, gives a major increase in bits-per-Hz. So, we can expect a more costeffective way of carrying greatly increased user data rates.

The 5G NGC will exploit several new network technologies within an IP integrated architecture [1], [2]. An important innovation is network slicing, whereby the capacity is partitioned so that an appropriate part through the NGC is dedicated to a service type or even an individual customer. This enables the operator to guarantee network performance, something new for IP networks. It also enables better network utilization since capacity can be used optimally for the class of traffic carried - with consequent operational cost savings for the operator.

New technologies that promise to reduce $5 \mathrm{G}$ network equipment costs are network functions virtualization in which many of the functions within the NGC are realized in software run on standard processors. Further economies can be gained by hosting the functions in one or more clouds. Crucially, the functions and network capacity can be applied dynamically, enabling tracking of instantaneous traffic demand - giving operational cost savings and potential new revenue opportunities. Further possible service features and capital cost savings are expected by deploying edge computing and, possibly, content-distribution network technologies.

The capital cost of $5 \mathrm{G}$ network deployment per bit of user data carried will decrease as will operational costs in managing $5 \mathrm{G}$ network capacity. However, the $5 \mathrm{G}$ network deployment will not be contiguous for many years, the existing $4 \mathrm{G}$ networks being needed to provide full mobile coverage - so the operators will have the burden of running two networks. This tension was neatly captured by

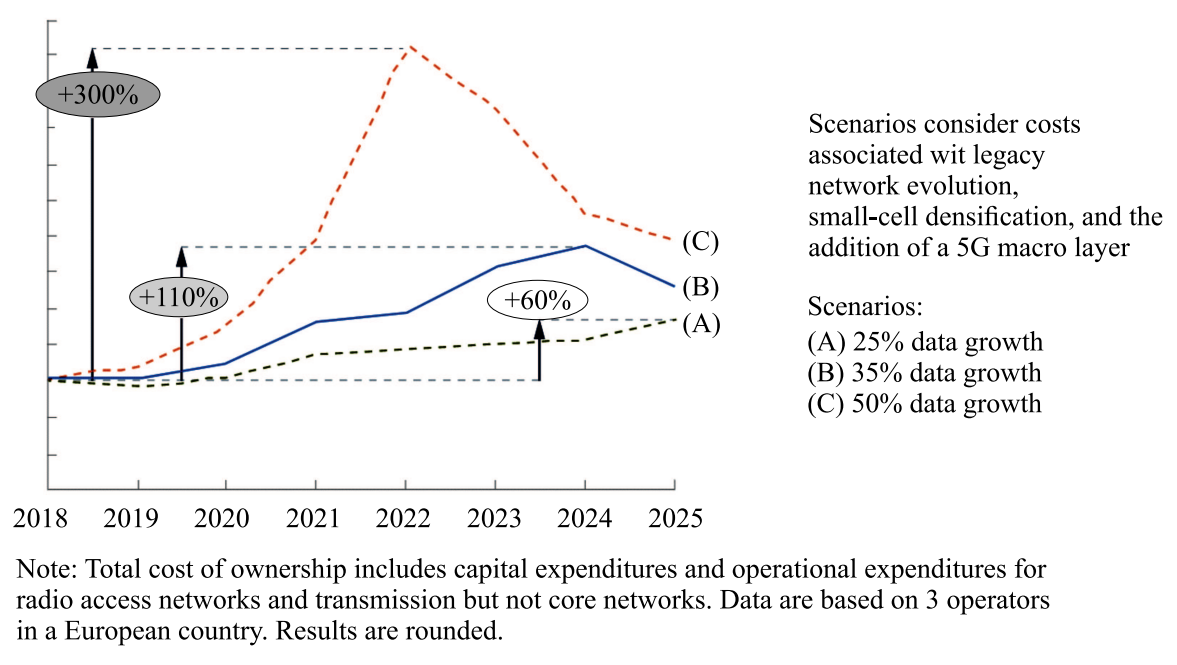

Fig. 2. Total cost of ownership of mobile networks over time [3]. 
McKinsey in a 2018 report [3]. The humps in the chart of Fig. 2 show cost of ownership of the radio access network (excluding core) peaking and then reducing as $5 \mathrm{G}$ build matures.

In conclusion, the capital costs of access and core network build are high and near certain. Spectrum costs have already been incurred. Parallel running will increase costs.

These investments create opportunities for improved network efficiency, where gains are probable but not guaranteed. They enable much higher data rates but whether operators will be able to generate significantly higher charges is not assured, and costs and revenues are dependent on assumptions about data growth where reasonable projections span a broad range. They enable new services, and thus new sources of revenue, though those opportunities will be contested between fixed and mobile networks and by MVNOs and service providers.

\section{New 5G Services}

Three types of use case are used as umbrella terms in describing potential $5 \mathrm{G}$ services:

- enhanced mobile broadband (eMBB),

- massive machine-type communications (mMTC),

- ultra-reliable low-latency communications (URLLC).

\section{1. $e M B B$}

In $5 \mathrm{G}$, mobile broadband will be "enhanced", especially at the radio layer, to provide:

- more extensive coverage,

- denser coverage in highly populated areas (e.g. stadiums, commuter train stations, shopping centers),

- higher capacity (more connections per area, more total data carriage per area),

- higher speeds and lower latency for individual users,

- mobility service while travelling at higher speeds,

- more overall reliability,

- content caching at the base station - "multi-access edge computing",

- seamless management of access method (mobile, public, and private $\mathrm{Wi}-\mathrm{Fi}$ ).

Table 1 shows the performance goals for eMBB.

Mobile operators will want to fill their new capacity quickly, and as efficiently as possible. Only in this way will the theoretical unit cost reductions (cost per bit per $\mathrm{Hz}$ ) be realizable. If this can be achieved, then operators could see profit growth from eMBB, even without premium pricing (other than for early adopters) - but the downside risk looms large.
Table 1

Performance goals for eMBB [4]-[5]

\begin{tabular}{|c|c|c|}
\hline $\begin{array}{l}\text { Use } \\
\text { case } \\
\text { area }\end{array}$ & Category & Performance goal \\
\hline \multirow{9}{*}{ eMCC } & \multirow{4}{*}{$\begin{array}{l}\text { Speed and } \\
\text { throughput }\end{array}$} & $1-10 \mathrm{Gbit} / \mathrm{s}$ connections \\
\hline & & $\begin{array}{l}\text { Cell aggregate throughput: } \\
20 \mathrm{Gbit} / \mathrm{s} \text { downlink (DL), } \\
10 \mathrm{Gbit} / \mathrm{s} \text { uplink (UL) }\end{array}$ \\
\hline & & $\begin{array}{l}\text { Indoor throughput } \\
10 \mathrm{Mbit} / \mathrm{s} \text { per } \mathrm{m}^{2}\end{array}$ \\
\hline & & $\begin{array}{l}\text { User experience } \\
\text { DL } 100 \mathrm{Mbit} / \mathrm{s} / \mathrm{UL} 50 \mathrm{Mbit} / \mathrm{s}\end{array}$ \\
\hline & Latency & $\begin{array}{l}4 \mathrm{~ms} \text { user plane, } \\
10 \text { to } 20 \mathrm{~ms} \text { control plane }\end{array}$ \\
\hline & \multirow{4}{*}{ Mobility } & Stationary $0 \mathrm{~km} / \mathrm{h}$ \\
\hline & & Pedestrian $10 \mathrm{~km} / \mathrm{h}$ \\
\hline & & Vehicular $10-120 \mathrm{~km} / \mathrm{h}$ \\
\hline & & High speed $120-500 \mathrm{~km} / \mathrm{h}$ \\
\hline
\end{tabular}

Most mobile operators are also fixed network operators. They can achieve economies of scope by running 5G fibre backhaul themselves, and by managing the access method for each device more efficiently. It could well be the case that some operators reflect these economies by offering a single solution for a device, a family or a small business. BT's recent promotions show signs of thinking along these lines, currently in the form of the converged "Halo" portfolios. So eMBB is an extension of home/office broadband and public Wi-Fi.

In principle, retail pricing for eMBB could also incorporate added-value elements, such as better experience in denselycovered areas, or "boost-it" temporary quality increments to, for example, speed up file transfer by caching it at the network edge.

Where these quality elements might be more relevant is in wholesale pricing to a wide collection of potential new service providers. These could range from virtual reality game providers, to highways agencies managing motorways, to factories and warehouses controlling robots and humans. Given the need to fill up their networks efficiently, networks may find themselves being as creative with wholesale pricing as they have been to-date with retail pricing.

\section{2. $M M T C$ and $U R L L C$}

This section explores some of the new opportunities created by mMTC and URLLC. The performance goals for these new technologies are summarized in Table 2.

The performance goals for mMTC and URLLC are based on the requirements of industry vertical sector use cases previously not supported by mobile network technologies. Although the requirements and needs have been known for a long while, e.g. industrial control systems, automotive telematics, connected health, in some cases the network economics, liability, security and performance have not 
Table 2

5G performance goals for mMTC and URLLC [4]-[5]

\begin{tabular}{|c|c|c|}
\hline $\begin{array}{c}\text { Use } \\
\text { case } \\
\text { area }\end{array}$ & Category & Performance goal \\
\hline mMTC & Density & $1,000,000$ nodes per $\mathrm{km}^{2}$ \\
\hline \multirow{2}{*}{ URLLC } & $\begin{array}{c}\text { Security and } \\
\text { reliability }\end{array}$ & Highly secure/resilient \\
\cline { 2 - 3 } & Latency & $\begin{array}{c}\text { Deterministic quality } \\
\text { of service (jitter and latency) }\end{array}$ \\
\cline { 3 - 3 } & $\begin{array}{c}\text { Low latency: } 1 \text { ms user plane, } \\
10 \text { to } 20 \text { ms control plane }\end{array}$ \\
\hline
\end{tabular}

matched requirements and hence services have not been deployed.

Addressing the new use cases will mean deployments into new areas, both virtually and physically, and may require the use of multiple networks to create the end-to-end connections required. These connections may need to be negotiated in real time to set up and tear down the required connection and agree the required service level agreements (SLAs) to ensure the QoS profile for the specific use case can be delivered. Once the connection is negotiated and agreed, slicing mechanisms can then be used to ensure the necessary QoS service parameters can be supported. Slicing is a network feature that enables the physical network infrastructure to be portioned to provide a QoS controlled end-to-end path for defined services.

There will be fierce competition for leadership in the delivery of new use cases. MNOs able to leverage existing assets such as spectrum, backhaul, radio, core, billing systems and sites together with new techniques and technologies like orchestration and slicing will be best placed to secure and consolidate this leading position. Orchestration is a policy-driven function to coordinate the hardware and software components of a network to automate the way network requests are managed and delivered.

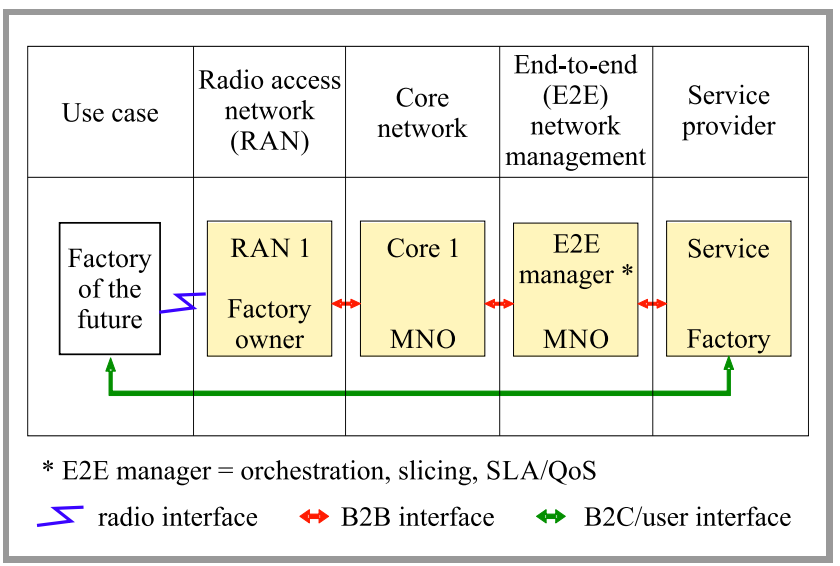

Fig. 3. Factory of the future, Industry 4.0 application.
Figure 3 shows a simple model to support an Industry 4.0 use case, two private entities collaborating, while Figs. 4-5 demonstrate some potential use cases.

In the example above, the factory location did not have good mobile coverage. In partnership with the MNO, the factory purchased and installed a $5 \mathrm{G}$ in-building radio access network (RAN), capable of eMBB, URRLC and mMTC functionality. The new network provided ability to run applications to operate critical control systems. Traditional mobile, telephony and broadband services can be enhanced through the indoor coverage, enabling one network investment to address multiple applications. The factory RAN is controlled by an MNO core and an E2E manager. The E2E manager could also be used for orchestrating other assets such as authenticated Wi-Fi or fixed communication technologies. The service provider is the factory which means that this could operate as a private network in the factory and, outside of the building, the employees would seamlessly connect to the MNO network.

Figure 4 shows a slightly more complex model where three entities are collaborating, two private and one public.

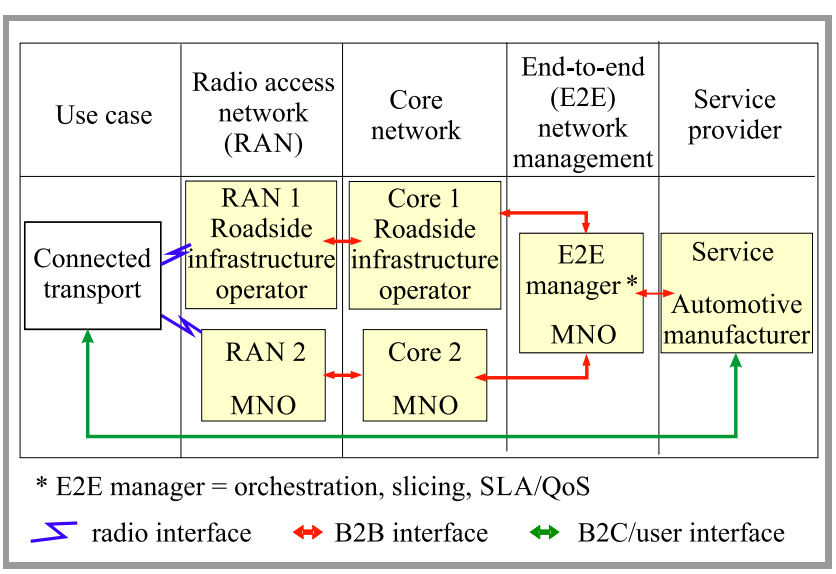

Fig. 4. Connected transport use case.

In this connected transport use case, two RANs are providing connectivity to the car, both with their own core network. Core 1 could be a separate physical network, or a virtual network operated by an MNO. The E2E management is being orchestrated by the MNO. The service provider is an automotive manufacturer. The approach on the RAN is based on a public roadside operator connecting $5 \mathrm{G}$ nodes to existing infrastructure to provide coverage to areas where traditionally the $\mathrm{B} 2 \mathrm{C}$ MNO did not provide adequate mobile coverage.

As with the factories of the future example, the network is capable of eMBB, MMTC and URLLC thereby allowing the infrastructure to support multiple applications such as private radio, vehicle-to-everything (V2X) applications, mapping, mobile telephony, and broadband. In some areas, where multiple networks exist, the car can transparently switch between the two RANs, managed by the E2E orchestrator. The relationship with the consumer is through the car manufacturer and hence the other entities are not visible to the user. 
The third example in Fig. 5 shows how such a modular business eco-system could address a local health and social care use case. In this case the complexity has increased again, reflecting the complexity and fragmentation of health and social care systems. The common approach enables applications such as telehealth, vital sign monitoring, secure large file transfer, robotic surgery, traditional mobile telephony, and broadband services to run over a common network infrastructure owned by multiple parties.

\begin{tabular}{|c|c|c|c|c|}
\hline Use case & $\begin{array}{c}\text { Radio access } \\
\text { network } \\
\text { (RAN) }\end{array}$ & $\begin{array}{l}\text { Core } \\
\text { network }\end{array}$ & $\begin{array}{c}\text { End-to-end } \\
\text { (E2E) } \\
\text { network } \\
\text { management }\end{array}$ & $\begin{array}{l}\text { Service } \\
\text { provider }\end{array}$ \\
\hline \multirow{3}{*}{$\begin{array}{l}\text { Health and } \\
\text { social care }\end{array}$} & \multirow{3}{*}{ 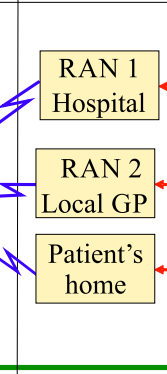 } & \begin{tabular}{|c|} 
Core 1 \\
Hospital \\
\end{tabular} & \multirow{3}{*}{$\begin{array}{c}\mathrm{E} 2 \mathrm{E} \\
\text { manager * } \\
\mathrm{MNO}\end{array}$} & \begin{tabular}{|l|} 
Service \\
Hospital \\
clinician \\
/records
\end{tabular} \\
\hline & & \multirow[t]{2}{*}{$\begin{array}{l}\text { Core } 2 \\
\text { MNO }\end{array}$} & & \multirow{2}{*}{\begin{tabular}{|c|}
$\begin{array}{c}\text { Service } \\
\text { GP/records }\end{array}$ \\
$\begin{array}{c}\$ \\
\begin{array}{c}\text { Service } \\
\text { Social care } \\
\text { provider }\end{array} \\
\end{array}$
\end{tabular}} \\
\hline & & & & \\
\hline \multicolumn{5}{|c|}{$*$ E2E manager $=$ orchestration, slicing, SLA/QoS } \\
\hline$\nabla$ radio & terface & B2B interfe & $\Leftrightarrow \mathrm{B} 2 \mathrm{C}$ & /user interface \\
\hline
\end{tabular}

Fig. 5. Health and social care use case.

Figure 5 shows three RANs in the hospital, GP surgery and the patient's home. None of these needs be owned by the MNO, although the MNO can be the orchestrator of the system and the fourth RAN could be the MNO which means the patient can also be connected outside of the three main RAN areas, providing service based on context and location.

Implementing this sort of extended multiple player value chain is a complex process. The work of the third generation partnership project (3GPP) will define and help create a common technology base, however we are still far from standardizing the commercial common approach for multiple network/business owner interactions, and further work is required.

\section{Conclusions}

$5 \mathrm{G}$ is being built in anticipation of a continuing and major growth in user data volumes. It will create a much greater capacity to connect and carry data traffic. But that comes at a cost - license fees, new access and core infrastructures, more cell sites and raised transitional costs during parallel running.

Capitalizing on the growth in data is not necessarily straightforward. Experience in fixed markets is that customers expect growing data capacity but not growing data prices. Competition will be fierce, between mobile network operators, fixed operators, MVNOs and service providers. It is likely that $5 \mathrm{G}$ build will create capacity greater than demand, at least for an interim period. Price pressures on simple data packages will be acute. The challenge for operators will be to avoid commoditization of data services, through bundling with other services and terminals, differential levels of quality or establishing and building brand and reputational values.

The initial signs are that MNOs are trying to find means of differentiating their $5 \mathrm{G}$ data service from those of their competitors. EE began by charging a premium for $5 \mathrm{G}$, aiming to capitalize on the enthusiasm of early adopters. Vodafone opted for innovation, dropping data limits and offering tiered pricing based on data speeds. Three positioned as the value for money player, offering $5 \mathrm{G}$ at no extra cost to existing customers. These initial positions will change as $5 \mathrm{G}$ build progresses and as market reaction to the different offers becomes apparent. But it is clear that $5 \mathrm{G}$ data prices will have to be innovative and find new sources of perceived user value to succeed.

$5 \mathrm{G}$ also creates new opportunities, both for greater levels of network efficiency and for new sources of revenue. Investor, regulatory and competitive pressures are likely to ensure that operational efficiencies are delivered, or that failure to achieve them is punished.

Capitalizing on new sources of revenue is more complex. The sorts of use cases enabled by $5 \mathrm{G}$ require new competences to deliver and bring new sources of competition into play. Solutions will tend to be customer or sector specific, to require management across a range of networks, often with different owners, and to require ongoing management and oversight.

This combination of bespoke solutions and ongoing support of complex systems requires development and stewardship resources largely new to MNOs. It means new forms of partnership working. It means new requirements for B2B interfaces, business models and SLAs. The good news for MNOs is that part of the skill set required is expertise in the management of interconnected network infrastructures and application of technologies such as orchestration and slicing. This should play to existing core strengths.

The less good news is that, although necessary, network skills are not sufficient. MNOs will have to consider whether to develop, recruit, acquire or partner in order to get service development, solutions architecture, customer relationship management, contracting and contract management, billing and other skills necessary for success. In part, that choice will be driven by whether MNOs wish to contribute to a solution, by supplying an off-the-shelf capability and leaving leadership, management and ownership to others, or whether they wish to take the more costly but potentially more lucrative alternative of owning and leading the solution themselves.

It is likely that pragmatism will prevail, with MNOs choosing to lead on solutions which rest heavily on their core strengths and moving to a supplier-basis for other contracts. A further revenue opportunity lies in wholesale markets, supplying network services to MVNOs and others who may compete at the retail level. Network slicing holds the prospect of a richer and more varied wholesale portfolio. The commercial opportunities of $5 \mathrm{G}$ are real but will not be 
straightforward to seize and capitalize upon. Where once mobile licenses were considered both a permit to operate and a license to print money, now they are a commitment to spend against a significantly less confident possibility of a return.

\section{Acknowledgement}

This article first appeared in the Institute of Telecommunications Professionals Journal (vol. 13, no. 2, 2019) and is published here with the kind permission of the ITP.

\section{References}

[1] A. Sutton, "5G Network architecture", J. of the Institute of Telecommun. Professionals, vol. 13, no. 4, pp. 19-25, 2019.

[2] A. Valdar, "Developments in telecommunications network architecture", J. of the Institute of Telecommun. Professionals, vol. 12, no. 4, pp. 27-33, 2018.

[3] "The road to 5G: the inevitable growth of infrastructure cost", McKinsey \& Co., 2018 [Online]. Available: www.mckinsey.com/ industries/technology-media-andtelecommunications/our-insights/ the-road-to-5g-the-inevitableinfrastructure-growth-of-infrastructurecost

[4] Recommendation ITU-R M.2410-0, 2017 [Online]. Available: https://www.itu.int/dms_pub/itu-r/opb/rep/ R-REP-M.2410-2017-PDF-E.pdf

[5] UK 5G Innovation Network, "Technical report on 5G network Architecture and Security", 2018 [Online]. Available: https://uk5g.org/ $5 \mathrm{~g}$-updates/research/technical-report-5g-network-architecture-andsecur/

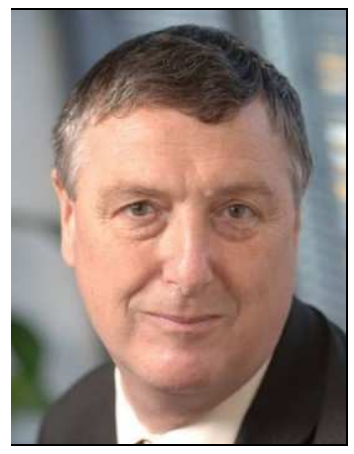

Peter McCarthy-Ward retired from BT in 2008 after 24 years in regulatory, marketing and strategic roles. From 2005 he was BT's Project Director for Ofcom's Strategic Review of the industry and for the development and implementation of the resulting undertakings. Peter runs the strategy, product management and marketing module of University College London's MSC, and sits on the ITP Journal's Editorial Board.

E-mail: peter.mccarthyward@btinternet.com

Freelance Lecturer \& Consultant

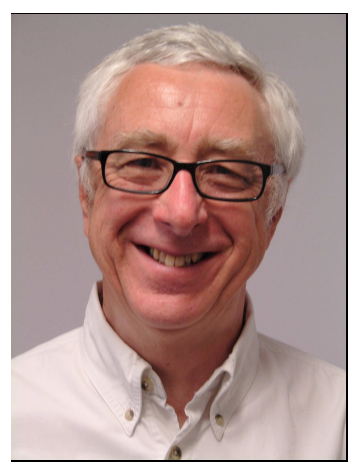

Andy Valdar has had a wideranging career in telecoms, covering network strategy, planning, standards, regulation, product management, as well as teaching and writing. After 30 years working for BT including three years on secondment to the UN in India, he joined University College London in 1999 directing MSc programmes. Now retired, he retains his Visiting Professor role at UCL and lectures on a part-time basis. Andy has authored four text books on telecoms, is a Director on the ITP board, former chairman of the ITPJ Editorial Board, and was President of FITCE Europe for three years. He is a fellow of the IET and ITP and is a Chartered Engineer.

E-mail: a.valdar@ucl.ac.uk

Visiting Professor

Department of Electronic \& Electrical Engineering

Faculty of Engineering Science

University College London

London, United Kingdom

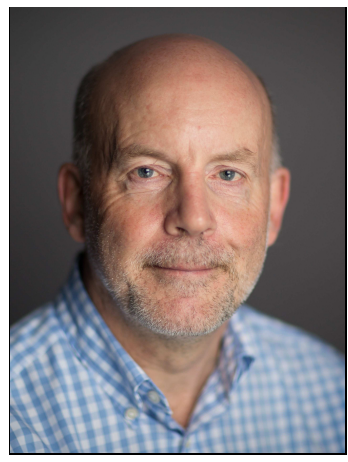

Stuart Newstead is a digital expert. He's been an expert for so long that he remembers when digital was called telecoms. He founded independent consultancy Ellare in 2002 and provides strategic and analytical advice to clients in over 20 countries. Clients include BBC, gigaclear, Squirro, Nominet, mi-Pay, Blackberry, BT, Oxfam, Zzoomm, Esprit Capital, Elliot advisers, Albion Ventures, plus a number of startups. Stuart was a Vice President at O2 until 2002 and, prior to that, a General Manager at BT.

E-mail: stuart.newstead@ellare.net

Ellare

Oxford, United Kingdom

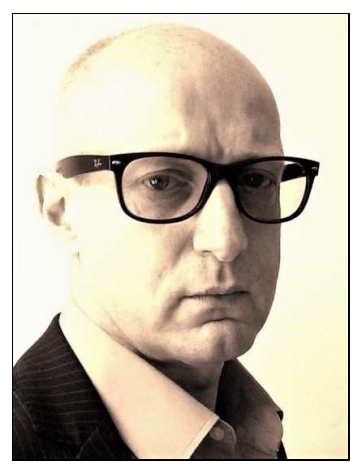

Stuart Revell is Managing Director of RTACS Ltd. An industry expert, covering both commercial and technical disciplines with over 35 years experience in the technology industry working for leading companies including Freescale Semiconductors, Motorola and Compare Industrial. Starting his career as an electronics design engineer, Stuart has experience in the semiconductors, electronics, hardware and software, ranging from industrial control systems through to complex ICT solutions, mobile and consumer solutions and has managed international teams covering both commercial and technical disciplines.

E-mail: stuart.revell@rtacs.com

RTA Communication Systems Ltd

London, United Kingdom 